\title{
LAS DECORACIONES BRUÑIDAS EN LAS CERÁMICAS GRISES ORIENTALIZANTES
}

\section{BURNISHED DECORATIONS IN GREY ORIENTALISING POTTERY}

\author{
por \\ JUAN IGNACIO VALLEJO SÁNCHEZ
}

RESUMEN Las cerámicas grises orientalizantes, producciones típicas de los siglos VII y VI a.C. en el mediodía peninsular, constituyen un claro ejemplo de la materialización de las relaciones entre dos tradiciones culturales diferentes -la fenicia y la indígena del Bronce Final-. Es posible rastrear estas conexiones a través del estudio formal y estilístico de estas vajillas. El análisis de las decoraciones bruñidas que se aplicaban sobre estos vasos -escasas pero significativas- nos confirma esas relaciones y orientan nuestras investigaciones sobre el significado histórico que tuvieron las cerámicas grises orientalizantes.

ABSTRACT

Grey Orientalizing Ware, typical productions of the $7^{\text {th }}$ and $6^{\text {th }}$ centuries $\mathrm{BC}$ in the peninsular south, constitute a clear example on which the relations between two different cultural traditions, the Phoenician and the Final Bronze Indigenous, are based.

It is possible to trace such connections through the formal and stylistic study of these vessels. Burnished Decorations analysis applied to these vases, scarce but meaningful, confirms these relations and direct our investigations about the historical meaning Grey Orientalizing Ware had.

\section{La cerámica gris orientalizante en la Península Ibérica.}

Desde finales del siglo VIII a.C. y sobre todo durante los dos siglos siguientes, aparece en los yacimientos del sur peninsular una especie cerámica fabricada a torno asociada a las producciones orientales: es la llamada cerámica gris orientalizante. La escasa, y en ocasiones ambigua investigación de la que ha sido objeto, provoca que continúe siendo un tema de actualidad. Este interés está subrayado por el potencial que nos ofrece su estudio como vía de análisis de la relaciones entre las poblaciones indígenas y las orientales, pues se trata de una producción que aúna ambas tradiciones cerámicas.

La relativa abundancia de producciones realizadas a torno y cocidas en atmósferas reductoras en todo el Mediterráneo, asociada a la desigualdad en el estado de los conocimientos de cada una de ellas, provocó que durante años predominase una tendencia excesivamente globalizadora, por la que elementos dispares 
se incluían dentro de un mismo conjunto (Vallejo 1998; Vallejo 1999). La mayoría de los estudios realizados sobre la cerámica gris orientalizante han centrado su atención última en determinar el origen desde el punto de vista formal y estético. Nunca se ha abordado con profundidad su verdadero significado histórico, es decir, analizar porqué surge un producto con las características que éste ofrecía en un momento determinado y no en otro. El conocer el origen formal es una parte de esta aproximación semántica, pero nunca la respuesta en sí.

Sobre este origen formal inicialmente se ha defendido una procedencia griega oriental. Esta hipótesis no hacía sino aplicar a las producciones occidentales, aún poco conocidas, las conclusiones a las que habían llegado los investigadores franceses para productos de similares características presentes en el Golfo de León (Jacobsthal y Neuffer 1933; Villard 1960; Benoit 1965). Aunque esta explicación es válida para el caso concreto de las costas del sureste francés, actualmente no puede admitirse para las producciones que aquí tratamos. La presencia de estas cerámicas de origen oriental está atestiguada en la Península Ibérica (Fernández-Jurado 1984; Cabrera 1987; Cabrera 1994), pero ni por las cronologías -en torno al siglo VI a.C.ni por los resultados de un análisis formal podemos establecer relación alguna con las primeras producciones del occidente andaluz.

La reactivación de los trabajos de campo en la Arqueología española y el "descubrimiento" de la colonización fenicia y de Tartessos como los dos grandes horizontes temáticos desde mediados de los años sesenta, posibilitó un progresivo y notable aumento del conocimiento arqueológico de la Protohistoria peninsular, particularmente andaluza. Estas circunstancias exigieron diferenciar por primera vez diversos grupos de cerámicas grises que aparecían en las costas andaluza, levantina y catalana y que anteriormente eran consideradas elementos de un mismo conjunto (Maluquer 1965; Aranegui 1969). Es en estos momentos cuando se comienza a valorar el papel de los fenicios en el proceso de formación de las cerámicas grises orientalizantes, aunque sin llegar a desterrar a los griegos del mismo. En líneas generales, se distinguieron áreas de influencia griega, centrada en el sur de Francia, Cataluña y Levante, y otras de influencia fenicia, extendida por toda la costa andaluza hasta Portugal (Almagro-Gorbea 1969; Aranegui 1975; Belén 1976).

A lo largo de la década de los ochenta asistimos a un cambio de orientación en las explicaciones propuestas y asumidas sobre este particular. De acuerdo con una tendencia generalizada en la Prehistoria española se le concede una mayor importancia a las dinámicas de las sociedades indígenas en los procesos de cambio sucedidos durante la Protohistoria. Desde entonces, el estudio de la tradición del Bronce Final ocupa un lugar imprescindible en la investigación sobre las cerámicas grises orientalizantes (Almagro-Gorbea 1977; Roos 1982; González Prats 1982; González Prats 1983; Lorrio 1988-1989; etc.). Se reconoce el papel preponderante de las tradiciones locales del Bronce Final, pero sin olvidar la participación de los elementos orientales en el proceso de definición de las cerámicas grises orientalizantes (Caro 1986; Caro 1989; González Prats 1983; Mancebo et al. 1992; Mancebo 1994 a; Vallejo 1999).

Esta trayectoria investigadora, brevemente resumida ${ }^{1}$, nos permite hablar de las cerámicas grises orientalizantes como un producto cerámico con personalidad propia. Constituyen un conjunto de vasos realizados a torno y cocidos en atmósferas reductoras, que les confiere su característico color gris. Se hallan presentes en la mayoría de los conjuntos materiales de los yacimientos del sur peninsular y áreas próximas-Extremadura, Suroeste, Sur de la Meseta, Sureste y Levante, Portugal y costa atlántica de Marruecos-durante los siglos VIII, VII y VI a.C. No existen grandes diferencias técnicas entre estas cerámicas y otras producciones de uso común, a excepción del método de cocción empleado y las citadas repercusiones sobre el color de las piezas. Gran parte de las formas documentadas son abiertas, entre ellas destacan los platos o fuentes de borde vuelto o en ala y los cuencos semiesféricos de bordes simples o engrosados.

1. Una visión más amplia es la ofrecida en Vallejo 1998. 
Podemos apreciar en estas cerámicas rasgos de diversa índole que nos remiten a las tradiciones fenicia y las del Bronce Final indígena. Pero una observación global de sus características estéticas generales nos induce a pensar en una mayor proximidad al mundo indígena que al oriental. Se trata de un producto que asume en gran parte unos principios estéticos, un gusto, que coincide más con los parámetros indígenas que con los fenicios. Además de las principales formas que presentan estas cerámicas, el propio aspecto de las superficies de los vasos y la aplicación de técnicas decorativas típicas del Bronce Final sur-peninsular, nos informan sobre esa relación. Centramos nuestro estudio en los materiales del Castillo de Doña Blanca, en el término gaditano del Puerto de Santa María, cotejando las informaciones que nos proporcionan con la escasa documentación publicada en el resto de la Península.

\section{Los tratamientos de acabado y las decoraciones en las cerámicas grises orientalizantes. Aspectos generales.}

\subsection{Los tratamientos de acabado.}

El alfarero, tras haber dado forma a las vasijas de cerámica gris antes de proceder a su cocción, solía acabar sus superficies con el alisado o el bruñido de las mismas. Éstas se frotaban repetidamente con algún instrumento, que era aplicado con el vaso aún apoyado sobre el torno, según se deduce de las líneas concéntricas que, con mayor o menor claridad, se pueden observar. Ambas técnicas se diferencian básicamente en la intensidad de la fuerza aplicada sobre las superficies, el grado de desecación de la pieza y el brillo final resultante, siempre más intensos en el caso de los bruñidos que en el de los alisados ${ }^{2}$. Además de la intencionalidad estética que tienen estos tratamientos, está demostrada su funcionalidad técnica, pues al homogeneizar las superficies y eliminar el exceso de agua, incrementan la impermeabilidad de la pieza, limitando y regulando así la circulación de líquidos (Wallace 1989; Schiffer 1990).

Este conjunto de técnicas tiene un uso frecuente y extendido en el tiempo. En el mediodía peninsular son bien conocidas desde, al menos, los inicios del Bronce (por ejemplo: Ruiz Mata 1975), si bien son más comunes durante el Bronce Final aplicadas a las cerámicas de mejor factura. Estos tratamientos se asociaban en ocasiones a otras técnicas decorativas -motivos pintados, incisos, etc.- (Gómez Toscano 1997: 234-235). A partir de mediados del siglo VIII a.C. se aplican a las cerámicas grises, además de a los vasos realizados a mano.

No existe en la aplicación de estas técnicas a las cerámicas grises orientalizantes un criterio cualitativo uniforme. Las calidades oscilan considerablemente en una amplia gama de intensidades, con las alteraciones de brillo, tono y tacto que de ello se derivan. Estas diferencias han servido como argumento para identificar producciones de diversa procedencia, reservándose un origen alóctono para aquéllas de mejor factura final y considerando las peor acabadas como el resultado de una producción local (Belén et al. 1977: 225-229, 244, 249-254, 292, 298; Pellicer et al. 1983: 178-179). De acuerdo con nuestras investigaciones no existe una asociación entre las formas y las calidades de las técnicas de acabado, lo que cabría esperar en el caso de un origen y concepción homogéneos ${ }^{3}$.

2. Resulta complejo, no obstante, proponer definiciones que sean compartidas por todos los investigadores. Este problema terminológico y de contenidos semánticos se agrava cuando buscamos el consenso internacional (Guerreshi 1980; Rye 1981; Cuomo di Caprio 1985; Gardin 1985; Balfet 1988; Levi y Recchia 1995).

3. La única excepción documentada por nosotros en este sentido la encontramos en las primeras producciones de mediados del siglo VIII a.C. en el Castillo de Doña Blanca y sobre todo en el vecino túmulo 1 de la necrópolis de Las Cumbres (Córdoba 1998; Vallejo 1999). 
Respecto a la utilización del engobe, resulta complicado distinguirlo de un bruñido de buena calidad, sobre todo por la propia naturaleza del recubrimiento, fabricado a partir de la misma arcilla muy fina y decantada. Unas superficies extraordinariamente pulidas, con brillo, muy suaves al tacto y sin marcas visibles de la aplicación del instrumento bruñidor pueden servirnos para identificar las vasijas grises así tratadas. Pero estas circunstancias no concurren siempre. Existe el riesgo añadido de interpretar como un verdadero engobe -es decir, aplicado sobre la superficie-el "auto-engobe" que resultaría del proceso de eliminación de agua por frotamiento de las superficies. Sin la aplicación sistemática de técnicas físico-químicas de análisis ceramológico resulta aventurado concluir más del estudio de visu realizado hasta aquí.

\subsection{Las decoraciones en las cerámicas grises orientalizantes.}

El recurso a la ornamentación no es frecuente en las producciones orientalizantes que aquí estudiamos, aunque tampoco inexistente ${ }^{4}$. La utilización de la pintura, en primer lugar, es casi anecdótica, a juzgar por el escaso volumen de los vestigios conocidos y conservados. Los distintos ejemplos publicados en Andalucía (Pellicer et al. 1983: fig. 65, 477; Campos et al. 1988: 31, figs. 42, 611 y 27, 494; Mancebo 1994b: 108) y otras regiones (Clausell et al. 1998: 61 y fig. 6, F 19, 20 y 21) presentan bandas pintadas, generalmente en la zona más próxima al borde ${ }^{5}$. En el Castillo de Doña Blanca conocemos algunos fragmentos cerámicos que presentan este tipo de decoración, como el soporte bitroncocónico aparecido en el túmulo 1 de la vecina necrópolis de Las Cumbres ${ }^{6}$. La excepcionalidad de este fenómeno en el sur peninsular no nos permite obtener conclusiones sobre su significado. Se ha planteado, sin embargo, una posible relación con algún tipo de ritual religioso, a partir de los paralelismos que ofrecen las decoraciones pintadas en rojo de las cerámicas y los huevos de avestruz fenicios, enlazados con la tradición autóctona de las decoraciones rojas -a la almagra- en el Neolítico y Calcolítico peninsulares (Mancebo 1994 b: 108).

La aplicación de otras técnicas, como la excisión, la incisión y el grabado, está mejor documentada, aunque a menudo en contextos de difícil lectura. Así ocurre, por ejemplo, con la única noticia cierta que tenemos de motivos geométricos excisos, en este caso rellenos posteriormente de una pasta blanca, en el fondo de un plato gris de Essaouira, en la antigua Mogador (Ruiz Cabrero y López Pardo 1996: 164 y fig. 2 f) ${ }^{7}$.

Las incisiones o grabados dibujan diversos motivos sobre las superficies, interpretados principalmente de dos formas (Almagro-Gorbea 1977; Mancebo 1994 b: 109). Muchos de los motivos geométricos conocidos -estrelliformes, zig-zags, rosetas, etc.- parecen tener un carácter eminentemente decorativo, quizás también simbólico (Carriazo 1973: 658, fig. 545; Belén et al. 1977: 320, fig. 148, 3; Lorrio 1988-1989: 311; Fernández Ochoa et al. 1994: fig.78, 75). Con el mismo carácter son considerados los ejemplos puntuales de representaciones figurativas documentados en Medellín (Lorrio 1988-1989: 311) y en el Cabezo de San Pedro (Blázquez et al. 1979: 171-172, fig. 66, lám. Ia). ${ }^{8}$

4. Por supuesto, obviamos considerar el bruñido de las superficies como un tratamiento exclusivamente decorativo dadas las repercusiones técnico funcionales que éste tiene.

5. Queremos manifestar nuestras reservas sobre la identificación por Carriazo de un "plato de cerámica gris, con vestigios de pintura roja muy deleznable" en el Poblado Bajo de El Carambolo (Carriazo 1973: 564, fig. 416).

6. Comunicación personal de D. Ignacio Córdoba Alonso y Da . Carmen J. Pérez Pérez.

7. Tenemos noticias de decoraciones similares en el cuadrante suroriental de la Meseta, gracias a la amable información facilitada por D. Jesús Arenas Esteban, si bien no tenemos certeza en cuanto a la caracterización de esas producciones como cerámicas grises orientalizantes.

8. En las excavaciones realizadas en Lisboa, en la sede central del Banco de Comércio Português, apareció un fragmento de un plato de cerámica gris con motivos esgrafitados, acompañados por cerámicas diversas con una cronología en torno al siglo V a.C., según apreciación de su excavador, D. Clementino Amaro. 
Otros motivos, generalmente signos alfabéticos, se han interpretado como marcas de alfarero para distinguir sus producciones, o como simples marcas de propiedad (Almagro-Gorbea 1977: 268-277; Ferrón et al. 1975; Pachón et al. 1979: 314 y 320, figs. 13, 2 y 17, 1; González Prats 1983: 230-231; Suárez et al. 1987: 17; Cunchillos 1994; Fernández Ochoa et al. 1994: 83; Mancebo 1994b: 108; Ruiz Cabrero y López Pardo 1996: 164, fig. 2-e, 176-179).

Aunque no podamos hablar estrictamente de decoraciones plásticas, quizás sí de ciertas "licencias" que dinamizan de algún modo las estandarizadas formas en las que se fabrica la cerámica gris. Entre estos recursos singulares podríamos citar la presencia de "baquetones", en número, frecuencia y disposición variables, que suelen resaltar la carena del vaso-recurso que llega a ser característico en los materiales de la desembocadura del Tajo (Barros et al. 1993) ${ }^{9}$.

\section{Las decoraciones bruñidas en las cerámicas grises orientalizantes.}

Sin lugar a dudas, la decoración de motivos geométricos bruñidos es la más usual entre las cerámicas grises orientalizantes, aunque nunca hasta el extremo de considerar su presencia como una característica generalizable. Conocemos su existencia en Niebla (Belén y Escacena 1990: 217, láms. IX: 4, 5; X: 8; XI: 13; XIV: 10, 11; XVII: 7; XXI: 9; XXII: 8), en el Cabezo de la Esperanza (Belén et al. 1977: 276, fig. 137, 29), en la Mesa de Setefilla (Aubet et al. 1983: 116, fig. 52,370), en El Carambolo (Carriazo 1973), El Castillo, en el término sevillano de Lora del Río (Remesal 1975: 3, nota 3), en el Cerro de San Cristóbal, de Estepa (Juárez 1997: 763, fig. 6). Contamos con importantes colecciones en el entorno inmediato de la desembocadura del río Guadalete, bahía de Cádiz y en la campiña jerezana ${ }^{10}$, destacando las de El Trobal, en Jerez de la Frontera, Vaina (Ruiz Mata y González Rodríguez 1994), y Castillo de Doña Blanca, en El Puerto de Santa María. La concentración de los materiales en un espacio relativamente delimitado en el Bajo Guadalquivir y la actual provincia de Huelva nos hacen pensar en una posible característica regional. No es, sin embargo, un fenómeno exclusivo, y podemos encontrarnos buenos ejemplos en otras latitudes y en otras épocas, como sucede en el Llanete de los Moros, en Córdoba (Martín de la Cruz 1987: fig. 53, 175), en La Bienvenida, Almodóvar del Campo, Ciudad Real (Fernández Ochoa et al. 1994: 82-83), Oreto (Nieto et al. 1980: 63, fig. 26, 9), El Cerro de la Cabeza, Valdepeñas (Vélez y Pérez Avilés 1987: lám. VIII, 42), o en Alcaçova de Santarém (Arruda y Catarino 1982: 37; Arruda 1983-1984: 223), o Conímbriga (Arruda 1997: 33, fig. 13). Es necesario, no obstante, mostrarse precavido ante estas producciones en la medida en la que no parecen responder a una misma y única tradición, aunque su sustrato parece encontrarse casi siempre en las culturas materiales precedentes de cada zona.

En efecto, los principales núcleos donde esta decoración aparece sobre las superficies de las cerámicas grises cuentan con una tradición ornamental análogas en otras producciones modeladas a mano del Bronce Final. Así ocurre en el suroeste andaluz, la baja Extremadura o Portugal, donde esta técnica decorativa constituye una de las características definitorias del Bronce Final, desde el siglo IX a.C., perdurando hasta el siglo VII e, incluso, el VI a.C. (Schubart 1971; López Roa 1977, 1978; Alarcón 1983; Pellicer 1989: 177-178; Gamito 1990-1992; Ruiz Mata 1995: 280-281; Bubner 1996; Gómez Toscano 1997: 234-235;

9. Hemos podido constatar personalmente este hecho gracias al conocimiento directo de parte de los materiales de Alcaçova de Santarém y de Quinta do Almaraz, que debemos a la amabilidad de la Prof ${ }^{a}$. Ana Margarida Arruda, de la Universidade Clásica de Lisboa, y a D. Luis Barros, del Museo Municipal de Almada, respectivamente.

10. Además de los materiales publicados, nos consta la existencia de otros materiales, unos expuestos en las vitrinas del Museo Arqueológico Municipal de Jerez de la Frontera, y otros en proceso de estudio por parte del personal de dicha institución. A ellos, especialmente a D. Francisco Barrionuevo Contreras y a Da . Rosalía González Rodríguez, queremos manifestar nuestro más sincero agradecimiento. 
Pavón 1998: 137-143). Más difícil es mantener esta afirmación en la submeseta sur, donde no existe una tradición evidente y continuada de dicha técnica (Fernández Ochoa et al. 1994: 82-83) sobre la que pudieran asentarse los ejemplares que la ostentan durante los siglos V, IV y III a.C. (Almagro-Gorbea 1978: 137; Nieto et al. 1980: 59; Vélez y Pérez Avilés 1987: 181; Fernández Ochoa et al. 1994: 82).

Esta técnica consiste en la ejecución de diversos diseños geométricos sobre la superficie interior o exterior de los vasos, que podía estar a su vez bruñida o alisada, y antes de la cocción de la pieza, ya seca. En algunas ocasiones, de la presión realizada con el instrumento bruñidor, siempre de punta roma, resultaban tenues acanalados que ensalzaban los motivos representados. Esta particularidad, que determina el uso de nomenclaturas específicas -decoración "pseudobruñida" o "pseudoacanalada" (Pavón 1998: 137, 140)-, la encontramos en algunos ejemplares de cerámicas grises orientalizantes del Castillo de Doña Blanca.

Las cuestiones planteadas por la investigación en torno al estudio de estas cerámicas con decoración bruñida se centraron en la posible relación y el grado de comunidad cultural entre las distintas regiones donde aparecían-Bajo Guadalquivir, Huelva, Algarve, Alentejo, Estremadura portuguesa y la baja Extremadura española-, y, conectando con esto, su origen, además de otras interrogantes relacionadas con aspectos formales, estilísticos y cronológicos. Son varias las propuestas de sistematización publicadas, como las de Almagro-Gorbea (1977: 125-132), Pavón (1998: 137-143) o Gamito (1990-1992: 286-289), basadas en criterios topográficos, estilísticos y/o tecnológicos. Se defiende en general una separación entre las cerámicas portuguesas y andaluzas (Schubart 1971: 164-167; López Roa 1977: 34; Bubner 1996: 67), aunque algunos autores matizan esta división (Gamito 1990-1992: 287; Pavón 1998: 137-143). Dentro de las andaluzas, el desarrollo de las investigaciones confirma la validez de la distinción entre las producciones onubenses y las del Bajo Guadalquivir (Ruiz Mata 1995: 280-281; Gómez Toscano 1997), señaladas ya por López Roa (1977, 1978).

Respecto al origen de esta técnica, siempre desde una perspectiva difusionista, las posturas se redujeron a la defensa de una procedencia o bien alóctona, nuclearizada en el Mediterráneo central (Schubart 1971: 176-177, en el caso de las cerámicas portuguesas) u oriental (López Roa 1977: 346), o en Centroeuropa (Garrido 1970); o bien autóctona, encontrando su sustrato más profundo en el Calcolítico y Bronce de la Andalucía occidental (Schubart 1971: 172-173; Ruiz Mata 1975; Pellicer 1989: 177).

La técnica de ejecución de las decoraciones bruñidas en las cerámicas grises orientalizantes no difieren de la empleada en las producciones manuales, descritas anteriormente. La simple comparación visual nos permite establecer esa similitud, corroborada a posteriori por un examen minucioso de las piezas más significativas.

Adelantábamos al principio la escasa incidencia de estas vasijas decoradas en el conjunto general de la documentación conocida. El recuento global de las cerámicas hasta ahora documentadas en el Castillo de Doña Blanca subrayan de nuevo la excepcionalidad de su presencia. Sólo el 0'15\% de las cerámicas grises del yacimiento presentan esta particularidad. Esta reducida población nos aconsejaría, en principio, la renuncia a cualquier intento de clasificación de los motivos decorativos que en ella encontramos, pero pensamos que este ejercicio de síntesis puede facilitar la organización y presentación de la información disponible, más aún cuando apenas existen precedentes bibliográficos sobre el particular (Vallejo e.p.).

En este ensayo de clasificación hemos optado por guiarnos preferentemente por dos criterios del cuadro compositivo: los elementos que organizan ese espacio y los motivos que integran los vanos creados. Dos son los elementos básicos que ordenan las composiciones: las grandes aspas bruñidas, que se interseccionan en el centro de la pieza; y las bandas bruñidas de anchura variable que acotan la superficie decorada en la zona próxima al borde, y que, en ocasiones, subdividen los vanos dejados por las aspas citadas al trazarse a media altura del perfil interior del vaso. Es muy usual, además, que el fondo interior del vaso quede resaltado con un bruñido concéntrico, donde se difumina la intersección de los brazos de la cruz central. Todas estas bandas que aquí citamos se conforman a partir de la unión de numerosas líneas trazadas, ejecutadas con el útil bruñidor, con poca superficie de trabajo, a juzgar por la observación detenida de los trazos efectuados. 
Los motivos decorativos, todos de carácter geométrico, se trazan en los espacios en reserva-únicamente alisados y rara vez bruñidos-que quedan entre los elementos ordenadores que veíamos -aspas y bandas concéntricas-. Podemos distinguir seis grandes grupos decorativos a partir de los motivos representados.

Grupo 1. La composición está presidida por una gran aspa bruñida, trazada sobre un plato carenado de borde vuelto, pero en esta ocasión los espacios libres entre sus brazos no presentan decoración alguna. Sólo tenemos documentado un ejemplar que responda a estas características, fechado en el siglo VII a.C. No conocemos ejemplos similares en otros yacimientos.

Grupo 2. Entre los brazos de la cruz de Malta central se trazan retículas bruñidas, generalmente de ojo romboidal (Fig. 2-1,2), y en algún caso cuadricular (Fig. 2-3). Estos motivos aparecen en el Castillo de Doña Blanca desde el siglo VIII a.C. hasta el VI a.C.; y en cerámicas grises de la campiña jerezana a lo largo del siglo VII a.C. (Ruiz Mata y González Rodríguez 1994: 241, fig. 10), del corte C del Cerro Macareno durante el siglo VI a.C., y de Niebla, desde finales del siglo V hasta el siglo II a.C. (Belén y Escacena 1990). Su relación con la cerámica a mano es indiscutible, conociéndose su uso en todo el Bajo Guadalquivir y Huelva (López Roa 1977, 1978; Ruiz Mata 1995; Gómez Toscano 1997), y estando presente en las producciones manuales conocidas en el mismo Castillo de Doña Blanca con las mismas cronologías (Fig. 4-1) y en otros yacimientos del entorno.

Grupo 3. Los vanos creados por el aspa central quedan ahora cubiertos por líneas en espiral o en zig-zag muy sinuosas (Fig. 1). En el Castillo de Doña Blanca estos motivos aparecen sobre cuencos semiesféricos y platos carenados de bordes exvasados de los siglos VII a.C. y VI a.C. La campiña jerezana nos ofrece nuevamente ejemplares similares a los del yacimiento portuense durante el siglo VII a.C. (Ruiz Mata y González Rodríguez 1994: 239, fig. 8, 1; 253, fig. 22, 3). A lo largo del VI a.C. estos motivos son reconocibles en cerámicas del Cerro Macareno y de Niebla, donde existen ejemplares más tardíos, fechados en el siglo II a.C. (Belén y Escacena 1990).

Grupo 4. Este grupo es similar al anterior, con la diferencia de que las líneas trazadas en los espacios en reserva forman zig-zags rectilíneos, de ángulos bien marcados (Fig. 2-4,5). Su presencia es especialmente significativa durante el siglo VII a.C. en el Castillo de Doña Blanca, apareciendo preferentemente sobre platos de borde vuelto, con algún ejemplar documentado en el siglo VI a.C. sobre cuencos hemiesféricos de bordes simples o engrosados. Este motivo es frecuente en otros yacimientos de Andalucía occidental, como en Setefilla, durante el siglo V a.C. (Aubet et al. 1983: fig. 52, 370), y en Niebla, entre finales del siglo V e inicios del IV a.C. (Belén y Escacena 1990). En la Meseta, esta decoración, que se relaciona con tradiciones distintas a las del Bronce indígena (Fernández Ochoa et al. 1994: 82-83), aparece puntualmente en algunos fragmentos de cerámica gris de mediados del siglo $\mathrm{V}$ a.C. de La Bienvenida (Fernández Ochoa et al. 1994: 82-83, figs. 70, 77, 78), en otros del siglo IV a.C. en Oreto (Nieto et al. 1980: 126, fig. 89). Las producciones más tardías las localizamos en el Cerro de las Cabezas (Vélez y Pérez Avilés 1987: 194, lám. VII, 42) y en Conímbriga (Arruda 1997: 33, fig. 13), entre los siglos IV y III a.C.

Grupo 5. La presencia del motivo central organizador es más que probable en este grupo, aunque no siempre tenemos evidencias de su existencia dado el estado fragmentario de las piezas estudiadas. La superficie interna del vaso -bien en su totalidad, bien afectando sólo a los espacios en reserva definidos por la cruz- se cubre de líneas rectas trazadas radialmente (Fig. 3-1,2). En el Castillo de Doña Blanca este motivo aparece desde finales del siglo VIII a.C., ejecutados sobre cuencos simples, siendo más numeroso durante el VII a.C., cuando aparece a los cuencos se añaden también los habituales vasos carenados de bordes exvasados, no faltando en el siglo VI a.C. Esta decoración no parece práctica habitual en otros yacimientos andaluces, extremeños o portugueses donde se conocen estas cerámicas decoradas.

Grupo 6. Las dudas razonables sobre la presencia del aspa central surgidas en el anterior grupo se repiten en el que ahora tratamos. Los espacios en reserva se decoran con una serie de líneas bruñidas dibujadas 
diagonalmente y de trazos variables (Fig. 3-3,4). Estas líneas pueden apoyarse sobre los brazos de la cruz de Malta que preside el conjunto (Fig. 3-4), o incluso sobre otras líneas radiales mucho más finas, resultando una suerte de motivo ramiforme (Fig. 3-3). En el Castillo de Doña Blanca, esta decoración se aplica mayoritariamente sobre los platos de bordes diferenciados exvasados. Los ejemplares se distribuyen cronológicamente entre los siglos VII a.C., principalmente, VI y IV-III a.C. La campiña jerezana y otros yacimientos de los alrededores nos proporcionan ejemplos de decoraciones de este grupo, datados en el siglo VII a.C. (Ruiz Mata y González Rodríguez 1994: figs. 8, 8; 10, 4; 22, 1 y 4).

Grupo 7. Tuvimos ciertas reservas a la hora de considerar la validez de este grupo debido a la incertidumbre sobre el verdadero valor estético de las líneas bruñidas radiales que, aparentemente, cubren toda la superficie interna de los vasos, limitadas por la banda que señala la zona del borde. Sin embargo hemos optado por otorgarle el beneficio de la duda, pues las líneas están claramente trazadas y no muestran la suavidad que apreciamos en la aplicación de otros bruñidos similares. Este trazado está documentado únicamente a lo largo del siglo VII a.C. en el Castillo de Doña Blanca, y se ejecutó sobre platos de borde vuelto y algún caso puntual sobre cuencos semiesféricos de bordes simples o engrosados.

Esta propuesta de sistematización no supone que los distintos motivos fuesen aplicados siempre de este modo. Existen algunos ejemplares que combinan las características de varios grupos, mezclando los motivos decorativos. Así ocurre con un vaso de El Trobal (Ruiz Mata y González Rodríguez 1994), que mezcla los espirales y los zig-zags de los grupos 3 y 4 , respectivamente.

Resulta absolutamente inevitable establecer una comparación entre estas decoraciones y las que presentan las cerámicas a mano del Bronce Final indígena (López Roa 1977, 1978). Sin ir más lejos, es posible localizar en el mismo Castillo de Doña Blanca materiales manuales que comparten estrechas analogías compositivas con los distintos grupos que hemos diferenciado (Fig. 4). La retícula bruñida del grupo 2 es sin duda uno de los ejemplos más emblemáticos extensibles a todo el Bajo Guadalquivir. En el citado yacimiento encontramos buenos ejemplares desde finales del siglo VIII a.C. hasta el IV a.C. No es extraño hallar vasos decorados con los bucles propios del grupo 3 en los siglos VII, VI y IV-III a.C. (Fig. 4-2). Las rectas zigzagueantes del grupo 4 cubren los interiores de piezas de los siglos VI y IV-III a.C. (Fig. 4-3). Mucho más abundantes son las líneas y bandas trazadas radial y diagonalmente, de los grupos 5 y 6 , frecuentes desde finales del siglo VIII a.C. a la última etapa de ocupación del hábitat (Fig. 4-4,5).

$\mathrm{Al}$ igual que ocurre con la vajilla manual, las cerámicas grises orientalizantes lucen estos ornatos en la superficie interior de los vasos. Un vistazo a la propuesta tipológica de López Roa $(1977,1978)$ no hace sino confirmar estas similitudes, que sin duda responden a algún tipo de fenómeno de interpretación o adaptación de unos motivos y unas técnicas que reproducen una estética muy determinada.

A conclusiones similares llegamos a través del análisis de las formas de las cerámicas grises orientalizantes. Las tipologías existentes (Belén 1976; Caro 1986; Caro 1989; Lorrio 1988-1989; Mancebo et al. 1992; Mancebo 1994; Vallejo 1999; etc.) permiten apreciar cómo en los repertorios de estas cerámicas encontramos rasgos y perfiles que remiten a las tradiciones del Bronce Final local y fenicia oriental. Algunas de estas vasijas parecen versiones -no simples imitaciones-de formas realizadas a mano durante el Bronce Final. Quizás esto guarde relación con la propia funcionalidad de la vajilla, probablemente de mesa o uso cotidiano, que determinó en gran medida las formas que se debían producir. Asimismo podemos apreciar cómo en algunos yacimientos del Suroeste -Cerro Macareno, Huelva, etc.- estas cerámicas a torno acaparan cada vez más un mayor porcentaje de la cerámica consumida, coincidiendo con un descenso inversamente proporcional de las producciones a mano.

De una forma u otra y en mayor o menor grado, es evidente que este fenómeno de "hibridación" tuvo lugar en la producción de las cerámicas grises orientalizantes. Apreciamos rasgos técnicos y formales que delatan la influencia oriental, como el propio uso del torno de alfarero o los perfiles fenicios que reproducen 
muchas de estas vasijas. Pero además observamos cómo se adoptan prioritariamente unos criterios estéticos y funcionales propios de las comunidades indígenas del Bronce Final y contemporáneos a la llegada de los fenicios. Admitir esta relación no es sino un mero punto de partida para la investigación. Indagar por qué sucede esto y en qué contextos específicos tiene lugar constituye el siguiente problema a abordar. Avanzar por este camino arrojará alguna luz sobre cómo se materializaron los tan mencionados procesos de interacción entre fenicios e indígenas en el sur de la Península Ibérica.

\section{Bibliografía.}

ALARCÓN, Ma.J. (1983): "Panorama actual de la cerámica con técnica de decoración bruñida", Boletín de la Asociación Española de Amigos de la Arqueología 14: 70-80.

ALMAGRO-GORBEA, M. (1969): La necrópolis de Las Madrigueras, Carrascosa del Campo (Cuenca). Madrid, Bibliotheca Praehistorica Hispana.

(1977): El Bronce Final y el Período Orientalizante en Extremadura. Madrid, Bibliotheca Praehistorica Hispana.

- (1978): "La iberización de las zonas orientales de la Meseta", Simposi Internacional: Els Origens del món ibéric (Barcelona-Empùries 1977), Ampurias 38-40: 93-156.

ARANEGUI, C. (1969): "La cerámica gris de los poblados ibéricos valencianos", Papeles del Laboratorio de Arqueología de Valencia 6: 113-131.

(1975): "La cerámica gris monócroma. Puntualizaciones sobre su estudio", Papeles del Laboratorio de Arqueología de Valencia 11: 333-379.

ARRUDA, A.M. (1983-1984): “Alcáçova de Santarém. Relatório dos trabalhos arqueológicos de 1984", Clio/Arqueologia-Revista de UNIARCH 1: 217-226.

— (1997): "Conimbriga: fouilles de 1988-1989, 2. Les travaux sur le forum", en: R. Étienne y F. Mayet (Eds.), Itinéraires lusitaniens. Trente années de collaboration archéologique luso-française: 255-273. Paris.

ARRUDA, A.M. y CATARINO, H. (1982): "Cerâmica da Idade do Ferro da Alcáçova de Santarém", Clio-Revista do Centro de História da Universidade de Lisboa III: 35-44.

AUBET, Ma .E.; SERNA, M.R.; ESCACENA, J.L. y RUIZ, M.M. (1983): La Mesa de Setefilla. Lora del Río (Sevilla). Campaña 1979. Madrid, Excavaciones Arqueológicas en España 122.

BALFET, H. (1988): Lexique plurilingue pour la description des poteries. Paris, CNRS.

BARROS, L.; CARDOSO, J.L. y SABROSA, A. (1993): "Fenícios na margem sul do Tejo. Economia e integração cultural do povoado do Almaraz-Almada", Os Fenícios no Território Português, Estudos Orientais IV: 143-181.

BELÉN, M. (1976): “Estudio y tipología de la cerámica gris de Huelva”, Revista de Archivos, Bibliotecas y Museos LXXIX, 2: 353-388.

BELÉN, M". y ESCACENA, J. L. (1990): "Niebla (Huelva). Excavaciones junto a la Puerta de Sevilla (1978-1982). La Cata 8", Huelva Arqueológica XII: 167- 305.

BELÉN, M.; FERNÁNDEZ-MIRANDA, M. y GARRIDO, J.P. (1977): Los orígenes de Huelva. Excavaciones en los Cabezos de San Pedro y la Esperanza. Huelva, Huelva Arqueológica III.

BENOIT, F. (1965): Recherches sur l'hellénisation du Midi de la Gaule. Marseille. (Reimp. de la $1^{\mathrm{a}}$. ed. 1980).

BLÁZQUEZ, J.M a .; RUIZ MATA, D.; REMESAL, J.; RAMÍREZ, J.L. y CLAUSS, K. (1979): Excavaciones en el Cabezo de San Pedro(Huelva). Campaña de 1977. Madrid, Excavaciones Arqueológicas en España 102. 
BUBNER, T. (1996): "A cerâmica de ornatos brunidos em Portugal", en: J. de Alarcão y A. I. Palma (Coord.), De Ulisses a Viriato. O primeiro milénio a.C.: 66-72, Lisboa.

CABRERA, P. (1987): El comercio griego en Huelva en época arcaica. Tesis Doctoral, Universidad Autónoma de Madrid.

-(1994): "Importaciones griegas arcaicas del Cerro del Villar (Guadalhorce, Málaga)", en: P. Cabrera, R. Olmos y E. Sanmartí (Coords.), Iberos y Griegos: lecturas desde la diversidad. Simposio Internacional celebrado en Ampurias, 3 al 5 de abril de 1991, Huelva Arqueológica XIII, 1: 98-125, Huelva.

CAMPOS, J.; VERA, M. y MORENO, T. (1988): Protohistoria de la ciudad de Sevilla. El corte estratigráfico San Isidoro 85-6. Sevilla, Monografías de Arqueología Andaluza 1.

CARO, A. (1986): La cerámica gris a torno orientalizante de Andalucía. Tesis Doctoral, Universidad de Sevilla. Microforma.

- (1989): Cerámica gris a torno tartesia. Cádiz.

CARRIAZO, J. de M. (1973): Tartessos y El Carambolo. Investigaciones arqueólógicas sobre la Protohistoria de la Baja Andalucía. Madrid.

CLAUSELL, G.; FERNÁNDEZ, F.; JORDAN, M.M. y SANFELIÚ, T. (1998): "Estudio arqueométrico de cerámicas arqueológicas del Torrelló del Boverot (Almassora, Castellón)", La Murà. Revista del Museu Municipal d'Almassora: 43-89.

CÓRDOBA, I. (1998): "Rituales de cremación durante la Protohistoria en el Mediterráneo y sur peninsular", en: J.L. Cunchillos, J.M. Galán, J.-A. Zamora (Eds.), Actas del Congreso "El Mediterráneo en la Antigüedad: Oriente y Occidente". Sapanu, Publicaciones en Internet, I [http://www.labherm.filol.csic.es]. Publicado también en CD-Rom.

CUNCHILLOS, J.-L. (1994): "Las inscripciones fenicias del Tell de Doña Blanca (I). Primera aproximación", en: A. González Blanco, J.-L. Cunchillos y M. Molina (Coords.), Coloquios de Cartagena, I. El mundo púnico. Historia, sociedad y cultura (Cartagena, 1990): 205-216, Murcia.

CUOMO DI CAPRIO, N. (1988): La ceramica in archeologia. Antiche tecniche di lavorazione e moderni metodi d'indagine. Roma.

FERNÁNDEZ-JURADO, J. (1984): La presencia griega arcaica en Huelva. Huelva, Monografías Arqueológicas. Colección Excavaciones en Huelva 1/1984.

FERNÁNDEZ OCHOA, C.;ZARZALEJOS, M.; HEVIA, P. y ESTEBAN, G. (1994): Sisapo I. Excavaciones Arqueológicas en "La Bienvenida", Almodóvar del Campo (Ciudad Real).Toledo.

FERRÓN, J.; FERNÁNDEZ-MIRANDA, M. y GARRIDO, J.P. (1975): “Inscripción fenicia procedente del Cabezo de La Esperanza (Huelva)”, Trabajos de Prehistoria 32: 199-211.

GAMITO, T. J. (1990-1992): "A cerâmica de retícula brunida do Castro dos Ratinhos (Moura)”, OArqueólogo Português série IV, 8/10: 277-297.

GARDIN, J.-C. (1985): Code pour l'analyse des formes des poteries. Paris.

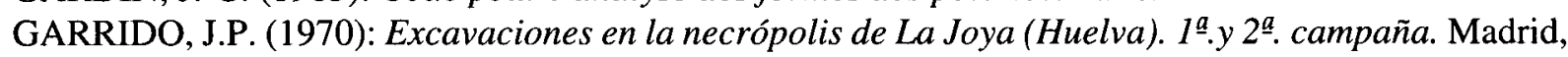
Excavaciones Arqueológicas en España 71.

GÓMEZ TOSCANO, F. (1997): El final de la Edad del Bronce entre el Guadiana y el Guadalquivir: el territorio y su ocupación. Huelva.

GONZÁLEZPRATS, A. (1982): “La Peña Negra IV. Excavaciones en el sector VII de la ciudad orientalizante 1980-81", Noticiario Arqueológico Hispánico 13: 309-418.

- (1983): Estudio arqueológico del poblamiento antiguo de la Sierra de Crevillente (Alicante). Anejo I de Lucentum, Alicante.

GUERRESHI, G. (1980): La tipologia della ceramica. Pordenone.

JACOBSTHAL, P. y NEUFFER, E. (1933): Gallia Graeca. Recherches surl'hellénisation de la Provence. Paris, Extrait de Prehistoire II- I. 
JUÁREZ, J. M. (1997): "Excavaciones de urgencia en el Cerro de San Cristóbal. Estepa (1993). Corte C”, Anuario Arqueológico de Andalucía 1993/ III Actividades de Urgencia: 759-765.

LEVI, S.T. y RECCHIA, G. (1995): "'La tecnologia del trattamento di superfici ceramiche: una descrizione analitica dei vasi dell' età del Bronzo di Grotta Manaccora (FG-Italia)", en: M. Vendrell-Saz, T. Pradell, J. Molera y M. García (Eds.), Estudis de Ceràmica Antiga. Actes del Simposi sobre ceràmica antiga (Barcelona, 1993): 67-72, Barcelona.

LÓPEZ ROA, C. (1977): "Las cerámicas con decoración bruñida en el Suroeste peninsular", Trabajos de Prehistoria 34: 341-370.

—_ (1978): "Las cerámicas alisadas con decoración bruñida", Huelva Arqueológica IV: 145-180.

LORRIO, A.J. (1988-1989): “Cerámica gris orientalizante de la necrópolis de Medellín (Badajoz)”, Zephyrus XLI-XLII: 283-314.

MALUQUER, J. (1965): "Una vasija excepcional del poblado ibérico de Mas Boscá", Pyrenae I: 241-250.

MANCEBO, J. (1993): "La cerámica gris a torno de la campiña sevillana", Actas del XXII Congreso Nacional de Arqueología (Vigo, 1993): 177-181.

_- (1994 a): "Las cerámicas grises a torno orientalizantes de la cuenca baja del Guadalquivir", en: J.M. Campos, J.A. Pérez y F. Gómez (Eds.), Arqueología en el entorno del Bajo Guadiana. Actas del Encuentro Internacional de Arqueología del Suroeste (Huelva, Niebla, 1993): 351-373, Huelva.

- (1994 b): "Consideraciones sobre la cerámica gris a torno de Montemolín (Sevilla)", Zephyrus XLVII: $105-111$.

MANCEBO, J.; DE LA BANDERA, Mª.L. y GARCÍA, J.M. (1992): "La cerámica gris a torno del yacimiento orientalizante de Montemolín (Sevilla)", Trabajos de Prehistoria 49: 277-293.

MARTÍN DE LA CRUZ, J.L. (1987): El Llanete de los Moros. Montoro, Córdoba. Madrid, Excavaciones Arqueológicas en España 151.

NIETO, G.; MESSEGUER, J. y POYATO, C. (1980): Oreto I. Madrid, Excavaciones Arqueológicas en España 114.

PACHÓN, J.A.; CARRASCO, J. y PASTOR, M. (1979): "Protohistoria de la cuenca alta del Genil", Cuadernos de Prehistoria de la Universidad de Granada IV: 295-340.

PAVÓN, I. (1998): El tránsito del II al I milenio a.C. en las cuencas medias de los ríos Tajo y Guadiana: la Edad del Bronce. Cáceres.

PELLICER, M. (1989): “El Bronce Reciente y los inicios del Hierro en Andalucía Occidental”, en: Tartessos. Arqueología Protohistórica del Bajo Guadalquivir: 147-187.

PELLICER, M.; ESCACENA, J.L. y BENDALA, M. (1983): El Cerro Macareno. Madrid, Excavaciones Arqueológicas en España 124.

REMESAL, J. (1975): "Cerámicas orientalizantes andaluzas”, Archivo Español de Arqueología 48: 3-21. ROOS, A.M. (1982): "Acerca de la antigua cerámica gris a torno de la Península Ibérica”, Ampurias 44: 43-70.

RUIZCABRERO, L.A. y LÓPEZPARDO, F. (1996): "Cerámicas fenicias con graffiti de la isla de Essaouira (antigua Mogador, Marruecos)", Rivista di Studi Fenici 26, 2: 70-89.

RUIZ MATA, D. (1975): "Cerámicas del Bronce del poblado de Valencina de la Concepción (Sevilla)", Madrider Mitteilungen 16: 80-110.

- (1995): "Las cerámicas del Bronce Final. Un soporte tipológico para delimitar el tiempo y el espacio tartésico", en: Tartessos: 25 años después (1968-1993). Actas del Congreso Conmemorativo del V Simposio Internacional de Prehistoria Peninsular (Jerez, 1993): 265-313, Jerez de la Frontera.

RUIZ MATA, D. y GONZÁLEZ RODRÍGUEZ, R. (1994): “Consideraciones sobre asentamientos rurales y cerámicas orientalizantes en la campiña gaditana", Spal 3: 209-256.

RYE, O.S. (1981), Pottery technology. Washington. 
SCHIFFER, M.B. (1990): "The influence of surface treatment on heating effectiveness of ceramic vessels", Journal of Archaeological Science 17, 4: 373-382.

SCHUBART, H. (1971): “Acerca de la cerámica del Bronce Tardío en el sur y oeste peninsular", Trabajos de Prehistoria 28: 153-182.

SUÁREZ, A.; LÓPEZ CASTRO, J.L.; GARCÍA, J.L.; SAN MARTÍN, C.; AGUAYO, P. y CARRILERO, M. (1987): "Memoria de la excavación de urgencia efectuada en el Cerro de Montecristo. Adra (Almería)", Anuario Arqueológico de Andalucía 1986/ III Actividades de Urgencia: 16-19.

VALLEJO, J.I. (1998): "Sobre el origen y extensión de la cerámica gris y las producciones occidentales", en: J.L. Cunchillos, J.M. Galán, J.-A. Zamora (Eds.), Actas del Congreso "El Mediterráneo en la Antigüedad: Oriente y Occidente". Sapanu, Publicaciones en Intenet, II [http://www.labherm.filol.csic.es]. Publicado también en CD-Rom.

(1999): La cerámica gris orientalizante del Castillo de Doña Blanca (El Puerto de Santa María, Cádiz). Memoria de Licenciatura, Universidad de Cádiz.

(e.p.): "Cerámicas grises decoradas bruñidas orientalizantes y decoraciones indígenas", Actas del XXIV Congreso Nacional de Arqueología (Cartagena, 1997).

VÉLEZ, J. y PÉREZ AVILÉS, J.J. (1987): "El yacimiento protohistórico del Cerro de las Cabezas (Valdepeñas)", Oretum III: 167-196.

VILLARD, F. (1960), La céramique grecque de Marseille (VI'. $-I V^{e}$. siècles). Paris.

WALLACE, D. (1989): "Functional factors of mica and ceramic burnishing", en: G. Bronitsky (Ed.), Pottery technology. Ideas and approaches, San Francisco-London, pp. 33-39. 

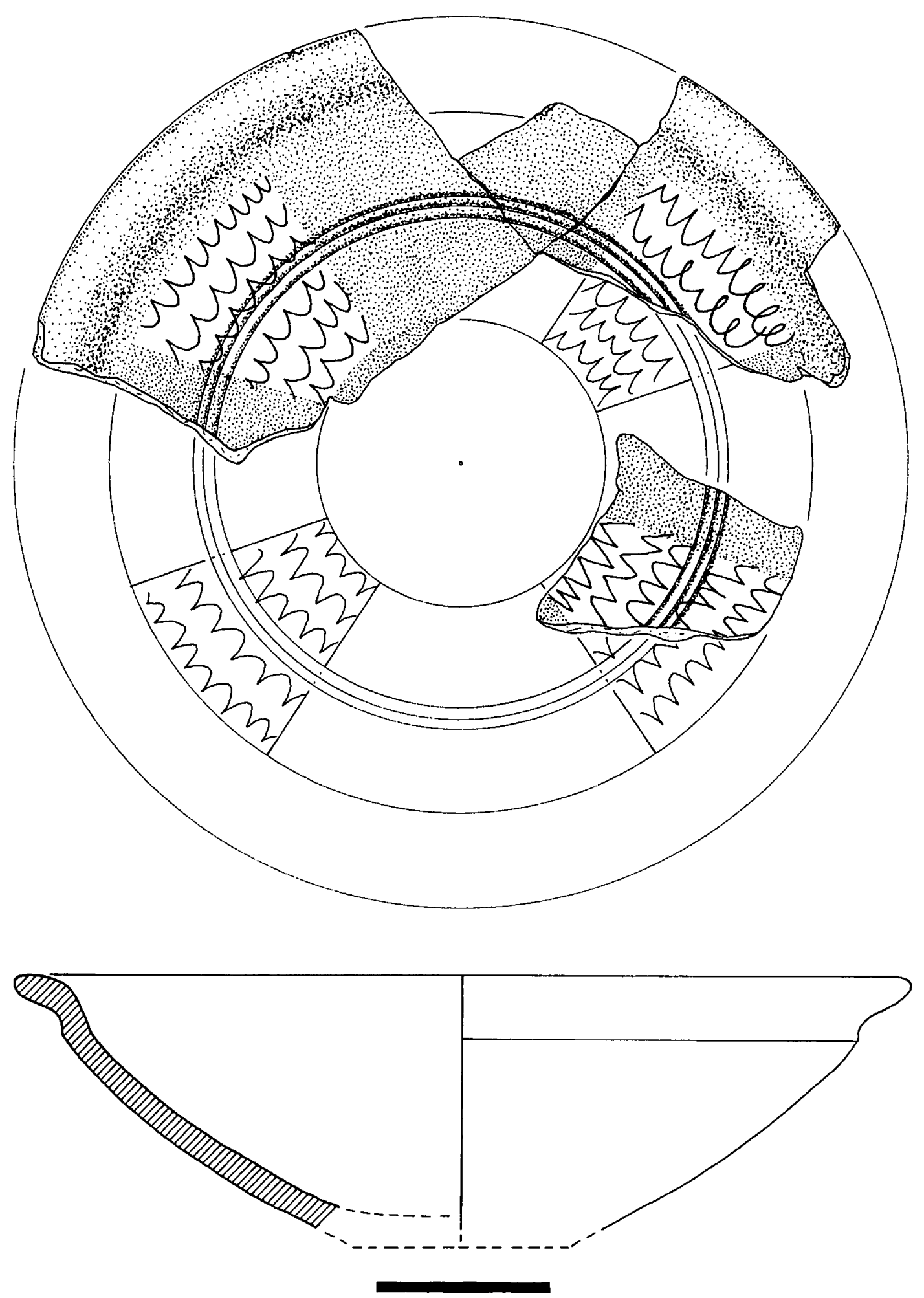

Fig. 1. Cerámicas grises orientalizantes con decoración bruñida del Castillo de Doña Blanca: grupo 3. 

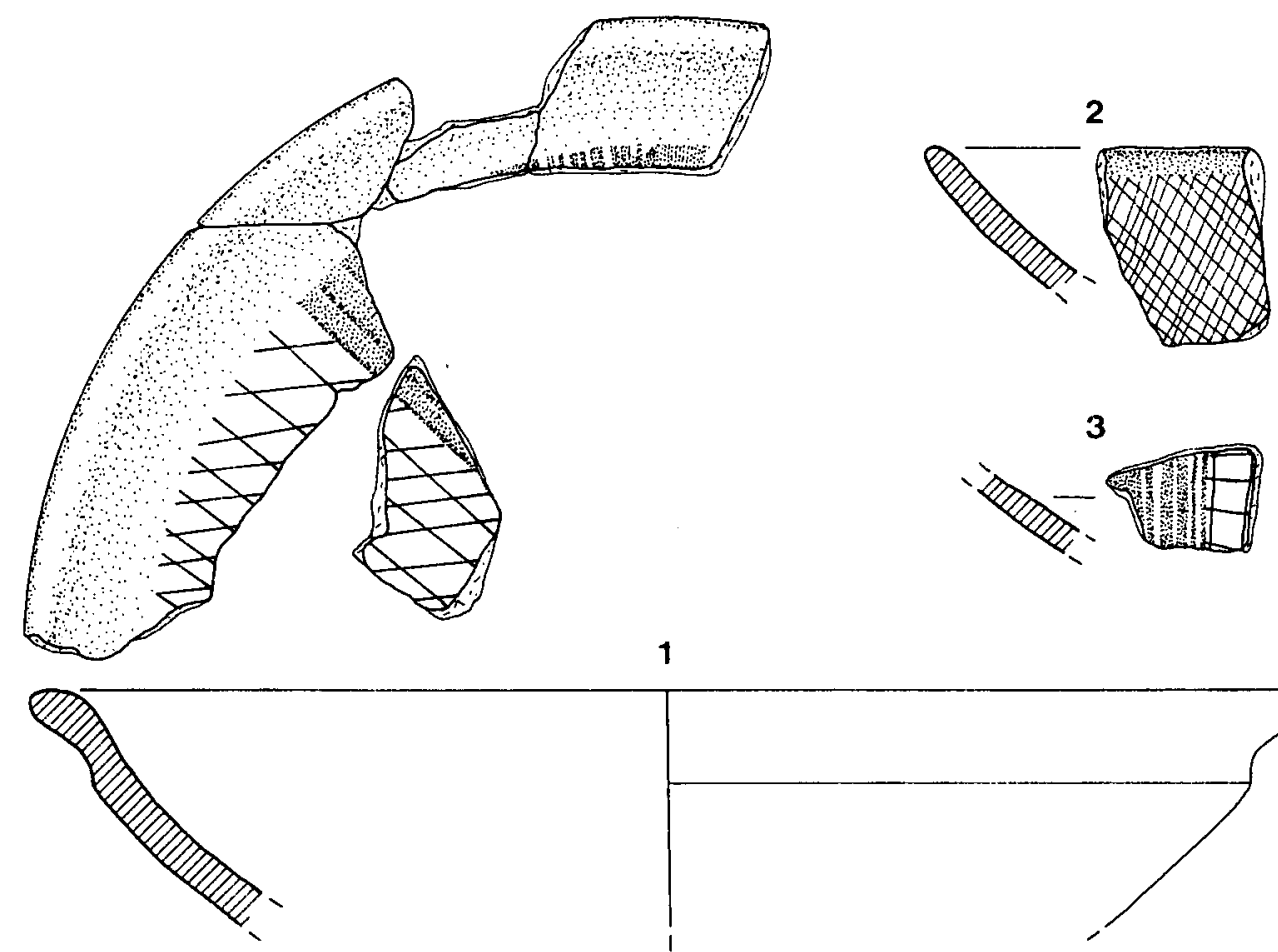

1
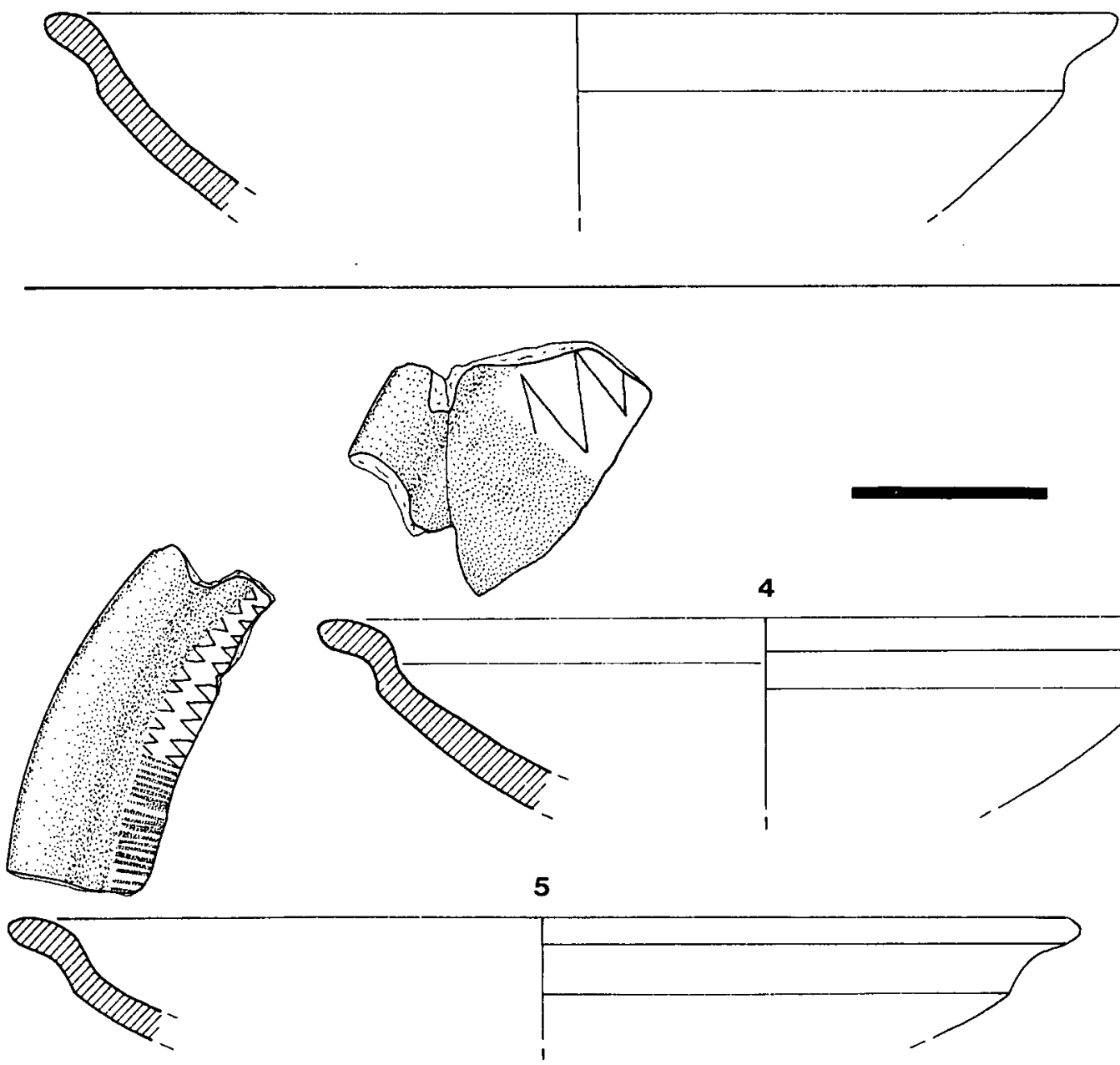

Fig. 2. Cerámicas grises orientalizantes con decoración bruñida del Castillo de Doña Blanca: grupos $2\left(\mathrm{n}^{\circ} .1-3\right)$ y $4\left(n^{\circ} .4-5\right)$. 

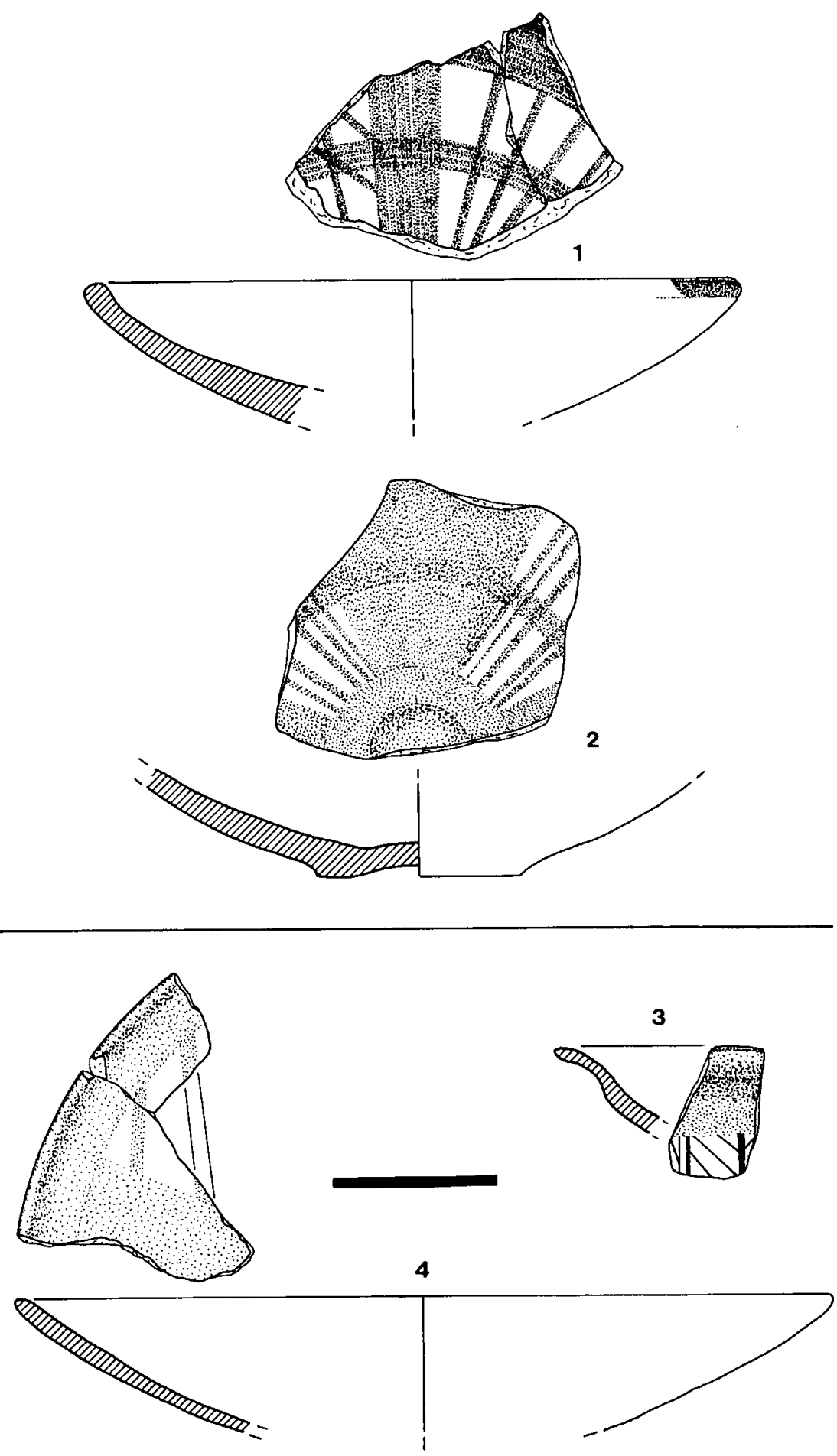

Fig. 3. Cerámicas grises orientalizantes con decoración bruñida del Castillo de Doña Blanca: grupos 5 ( $n^{\circ}$. 1-2) y $6\left(n^{\circ} .3-4\right)$. 

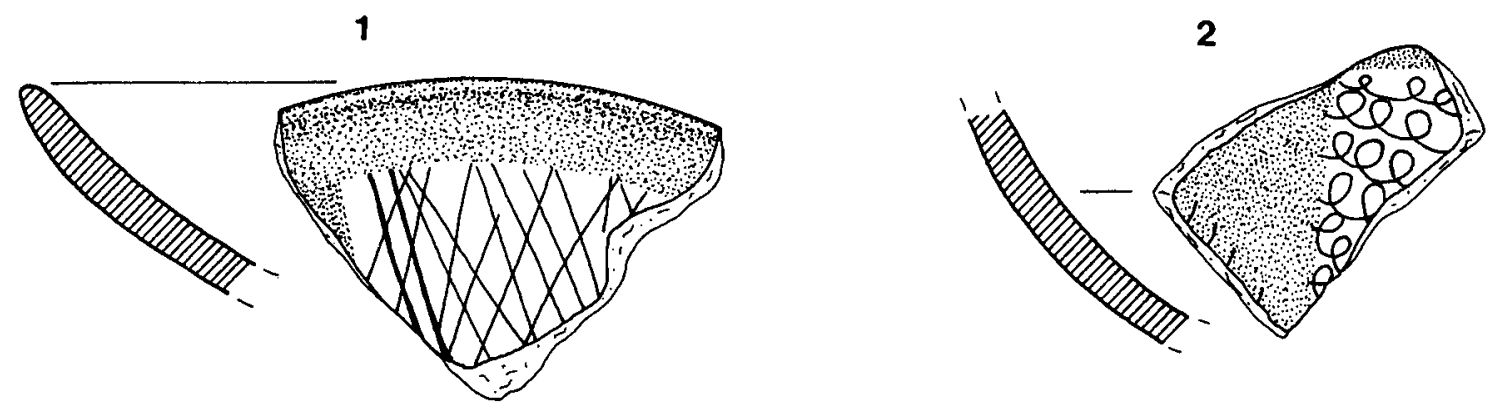

3
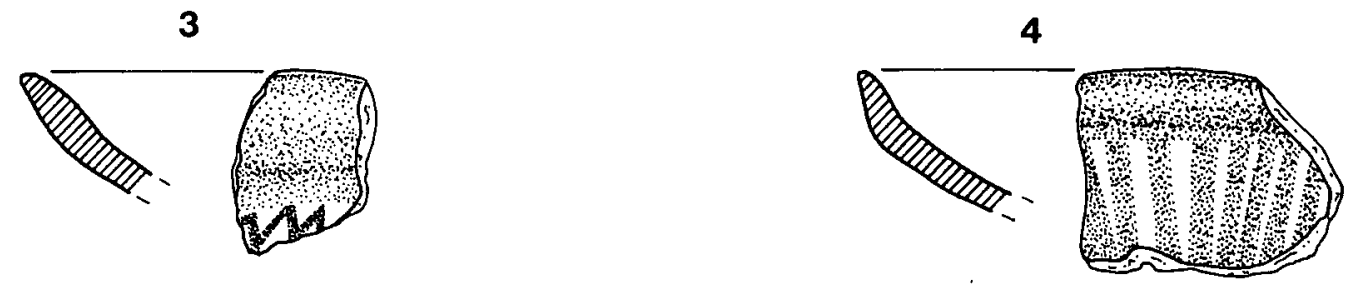

Fig. 4. Cerámicas a mano con decoración bruñida del Castillo de Doña Blanca. 